\title{
The Gothic tower of Freiburg Minster, Germany: analysis and repair
}

1 Rainer Barthel Prof. Dr.-Ing.

Partner, Barthel \& Maus, Beratende Ingenieure $\mathrm{GmbH}$, München, Germany; Professor, Technische Universität München, München, Germany
2 Joram Tutsch Dipl.-Ing

Technische Universität München, München, Germany (corresponding author: joram.tutsch@tum.de)

3 Joseph Jordan Dr.-Ing

Barthel \& Maus, Beratende Ingenieure GmbH, München, Germany
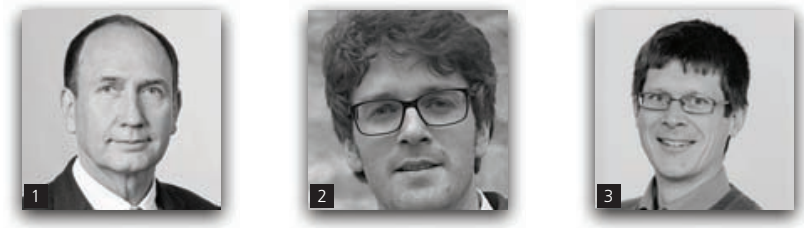

The filigree spire of the 116-m-high west tower of Freiburg Minster, Germany was completed around 1330 AD and is an architectural monument of the highest rank. At $\mathbf{4 5} \mathrm{m}$ high and constructed using tracery throughout, the spire is the tallest of its kind ever built (Kayser, 2014). It has survived until the present without major damage or alteration. In 2010, after several flaws in the sandstone were detected, a detailed damage survey and a structural analysis were initiated. This paper provides a description of the construction of the spire, the damaged sections that were detected, the material tests and statical calculations undertaken and the implementation of repair measures. A threedimensional digital model, showing all structural elements, historical alterations and damage, played a particularly important role in understanding the construction and the statical behaviour of the spire. Wind tunnel measurements and a series of material tests were conducted to ensure a realistic estimation of the stability under wind and seismic load. The analysis and the tests are still ongoing; nevertheless, some substantial results can already be presented.

\section{Introduction}

Freiburg is situated in south-western Germany on the edge of the Black Forest, close to the French border. The construction of the Freiburg Minster began in around 1200, originally in the Romanesque style, on the site of an even older church. From 1230 onwards, the master builders adopted the Gothic style. The tower was completed in around 1330. It is $116 \mathrm{~m}$ high and has survived until the present without major damage or alteration (Figure 1).

The outstanding feature of the tower is the filigree construction of the pointed spire. The spire has the shape of an octahedral pyramid and consists exclusively of an exterior structure without any internal supports. On a platform roughly $55 \mathrm{~m}$ above the ground, one is in a space with a height of nearly $50 \mathrm{~m}$ completely enclosed by tracery (Figure 2). The Swiss historian Jacob Burckhardt (1818-1897) once said that this tower 'will forever remain the most beautiful spire on earth'. His remark gave rise to the frequently used misquote of the most 'beautiful tower in the whole of Christianity'.

Since its construction, no major alterations were undertaken and no strengthening measures have been required. The tower survived several catastrophes. One of the most destructive earthquakes in northern Europe occurred in 1356, destroying many buildings in the Swiss city of Basel, just $30 \mathrm{~km}$ away from Freiburg. It also survived the bombing raids of November 1944, which destroyed all the houses on the west and north sides of the minster.

Nevertheless, the masonry and the tracery had to be repaired at regular intervals, for instance in the 1920s and 1960s. In 2009, a scaffold was erected once again after small pieces of stone fell onto the viewing platform. Originally, the intention was to undertake local repairs and stone conservation. After the scaffolding was erected and the spire made accessible, further damage and cracks were discovered, which proved to be much more dangerous than expected. In particular, the so-called cornerstones of the main struts of the octagon, which are structurally essential, showed several cracks. Following these discoveries, author Barthel was put in charge of an investigation (Barthel et al., 2012). The crucial questions were, what were the causes of this cracking and what kind of remediation measures would be necessary?

\section{Construction}

The lower part of the tower is square in plan and very solid with only a few openings (Figure 3). At $40 \mathrm{~m}$, there is the so-called star gallery and the belfry. Above the belfry, at the height of $55 \mathrm{~m}$, 
Engineering History and Heritage Volume 169 Issue EH2
The Gothic tower of Freiburg Minster,

Germany: analysis and repair

Barthel, Tutsch and Jordan

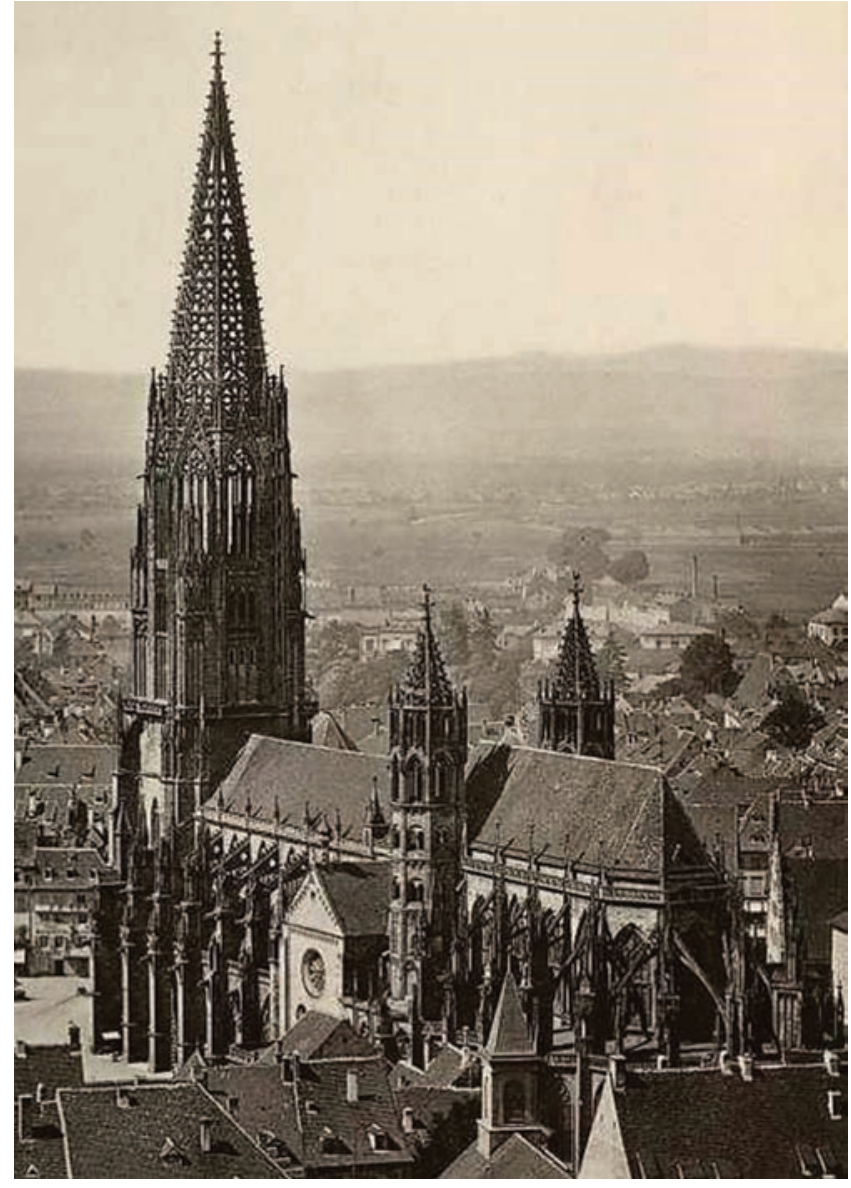

Figure 1. Freiburg Minster, postcard, early twentieth century

there is an internal platform. From there the tower is octagonal and free from any internal structure - there are no walls, only pillars and high tracery windows. At the height of $72 \mathrm{~m}$, there is a further gallery on the outside. Above that level, the octagonal spire rises.

The spire is subdivided into a solid base, seven storeys of tracery elements between levels 1 and 8 (Figure 4) and the pinnacle incorporating the finial (Figure 5). Circumferential wrought-iron ties are situated on eight levels.

The construction consists of eight struts in the corners of the octagon, the tracery panels and the iron ties (Figure 6). Further special elements are the cornerstones, which form part of the struts, and the horizontal chords, which form the upper and lower edges of the tracery panels. The construction materials are sandstone, wrought iron, lime mortar and lead.

Between levels 2 and 8, the tracery panels and the struts are not interlocked; there is a vertical joint running through, which is filled with lime mortar. The size of the cut stones inside the tracery is up to $2 \mathrm{~m}$. The thickness of the tracery is $58 \mathrm{~cm}$ in the first four storeys and reduces to $43 \mathrm{~cm}$ in the upper storeys.

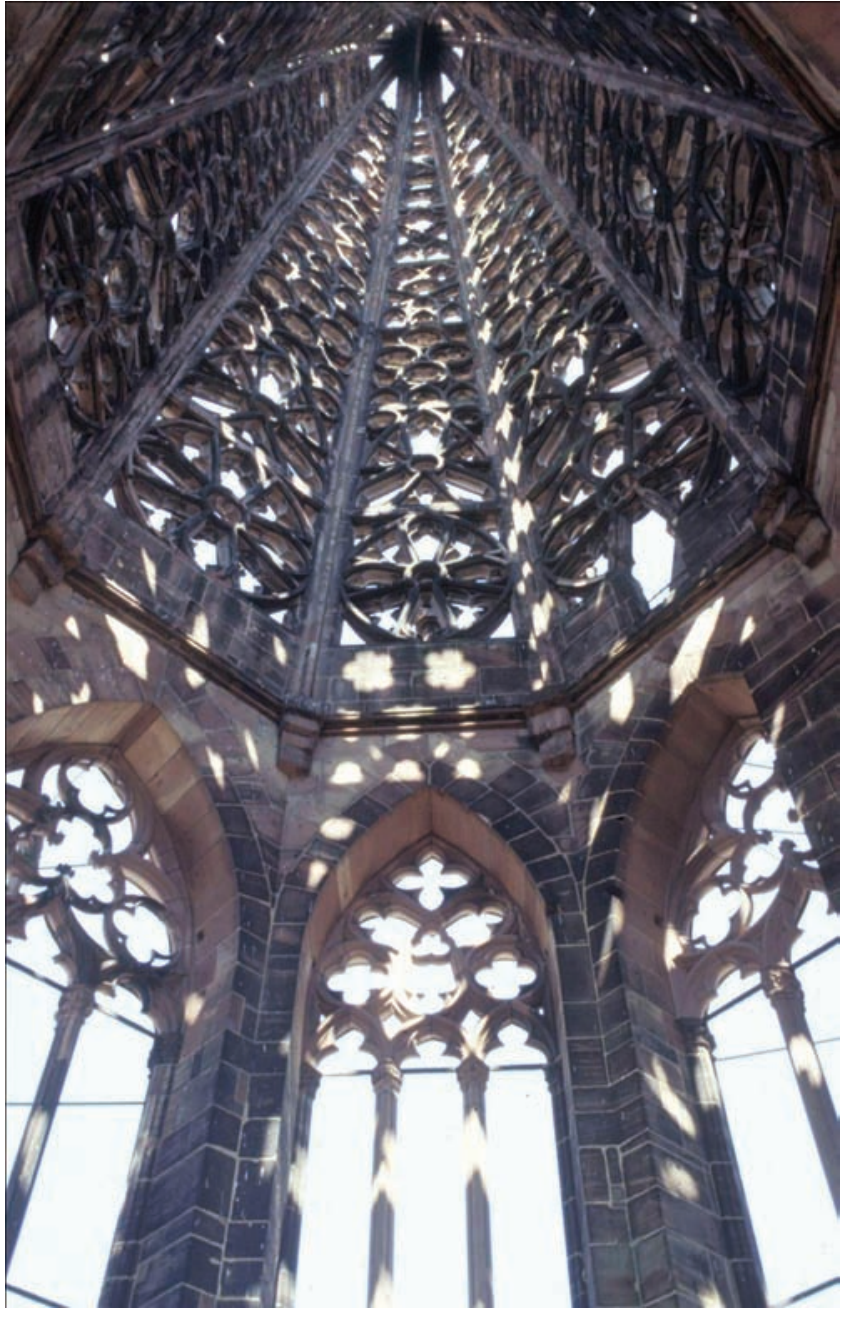

Figure 2. View from the octagon level inside the spire

In detail, the structure is very straightforward and logically organised (Figure 7). At the level of the iron ties, the joints are all horizontal. This is a geometrical precondition for the connection of the ties to an iron ring at the cornerstones. The joints in the struts are always horizontal, while the joints inside the tracery panels are perpendicular to the outer surface of the spire. In plan, the vertical joints inside the chords are also perpendicular to the outer surface.

The sediment layers of the sandstone are horizontal at the struts. Inside the tracery panels, the layers are parallel to the outer plane of the spire. The horizontal joints in the struts and the chords where the ties are positioned are filled with mortar. The joints inside the tracery are filled with lead.

The cross-section of the iron ties varies between $3.8 \mathrm{~cm} \times 3.0 \mathrm{~cm}$ and $4.5 \mathrm{~cm} \times 3.5 \mathrm{~cm}$ (Figure 8 ). The connection at the cornerstones consists of a hook at the end of each tie and a wrought-iron ring. The iron ties and the ring are embedded in the cornerstone. Lead was poured into the interstices inside the ring and between the iron and the sandstone. 
The Gothic tower of Freiburg Minster,

Germany: analysis and repair

Barthel, Tutsch and Jordan

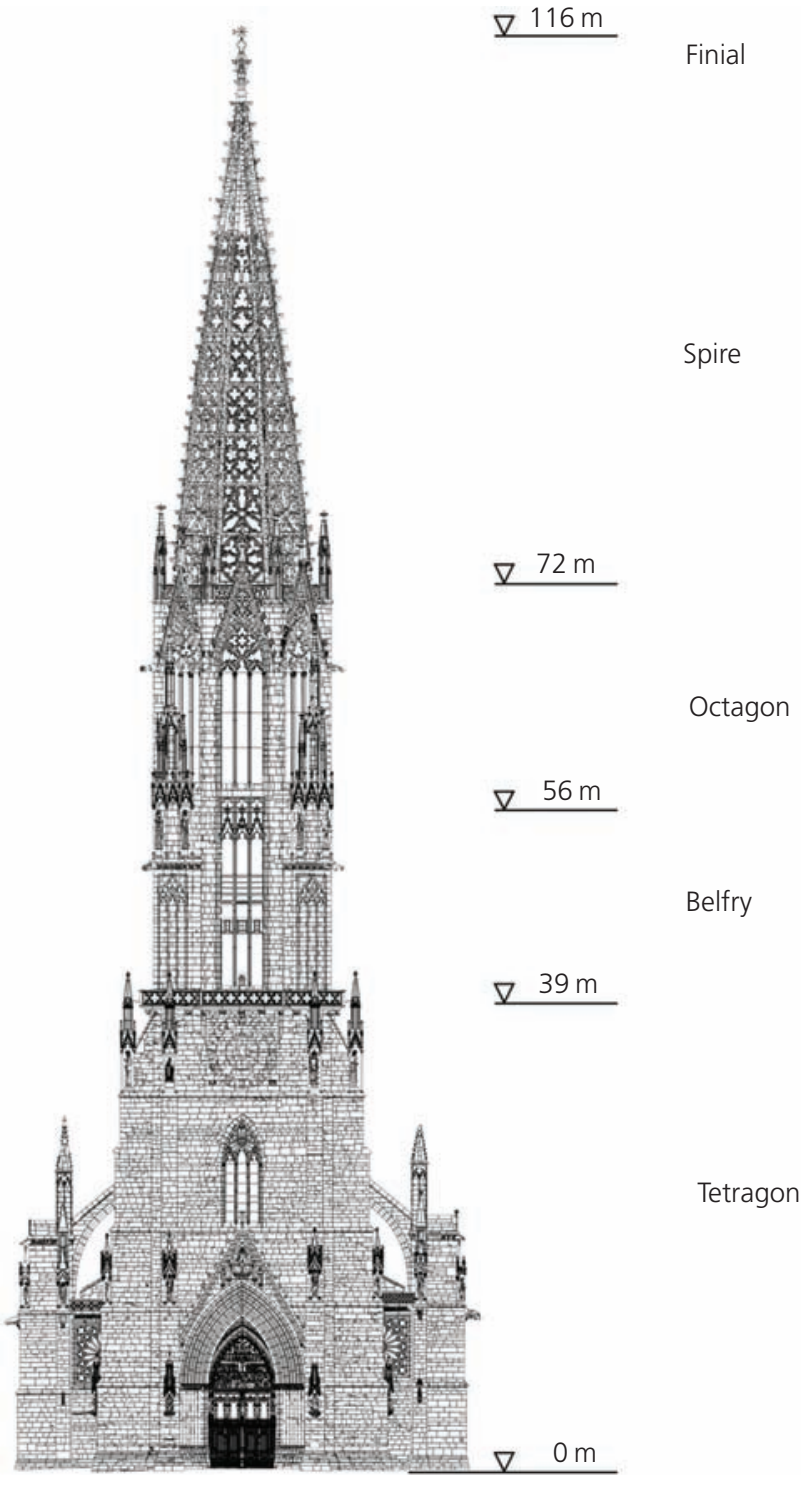

Figure 3. West elevation of Freiburg Minster (GBVD mbH, Müllheim, Germany)

At the first storey, between levels 1 and 2, the construction is much more complicated (Figure 6). Here the stones of the strut and the tracery are interlocked, which leads to a very tricky geometry. The inclinations of the joints are different, even within one single stone. Connections to the tracery are perpendicular to the outer surface; joints between the stones of the struts are horizontal. The joints inside the tracery are reinforced by iron pins embedded accurately in lead. It can be assumed that after the completion of the first storey, it became obvious that this construction method was too time consuming and a simpler method had to be applied.

At the pinnacle the struts are closer to one another and there is no tracery in between. At the very top the pinnacle is solid and there are a more irregularities in the construction, including many iron

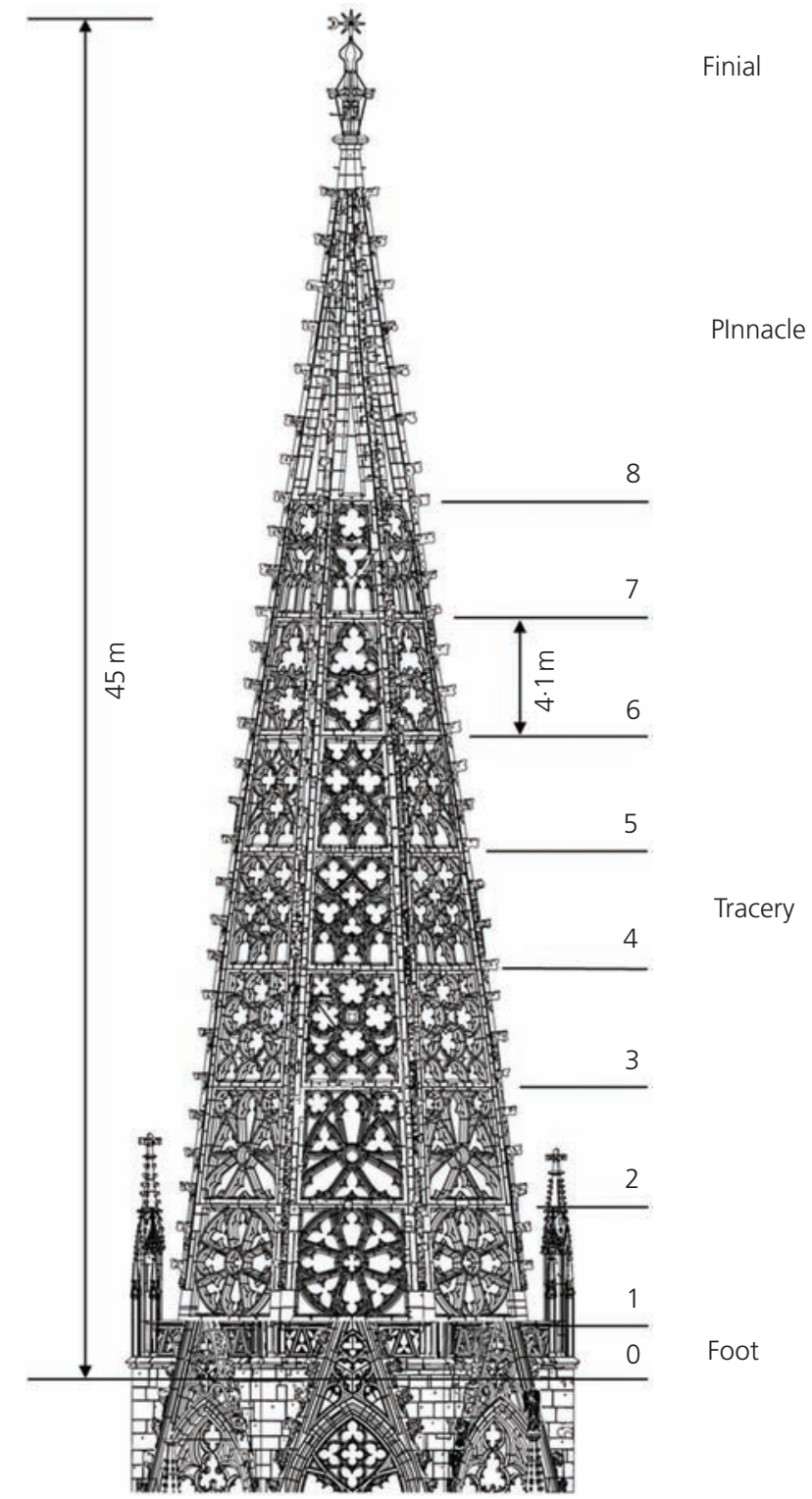

Figure 4. Elevation of the spire (GBVD mbH, Müllheim, Germany)

cramps (Figure 5). The finial is anchored by a vertical tie rod to the solid section underneath.

\section{Damage to the structure}

A detailed damage survey revealed that there were many more places where damage had occurred than had been visible initially. When the first cornerstone, mentioned earlier, was removed, it was found to be destroyed completely; what remained was a mere stump (Figure 9).

Numerous cornerstones showed similar damage, and some were found to have been repaired rather crudely in former times. It is difficult to repair such a cornerstone in an adequate way. The vertical load on a cornerstone is up to $400 \mathrm{kN}$ and masons in the fifteenth or sixteenth centuries were well aware that it could be 
Engineering History and Heritage Volume 169 Issue EH2
The Gothic tower of Freiburg Minster,

Germany: analysis and repair

Barthel, Tutsch and Jordan
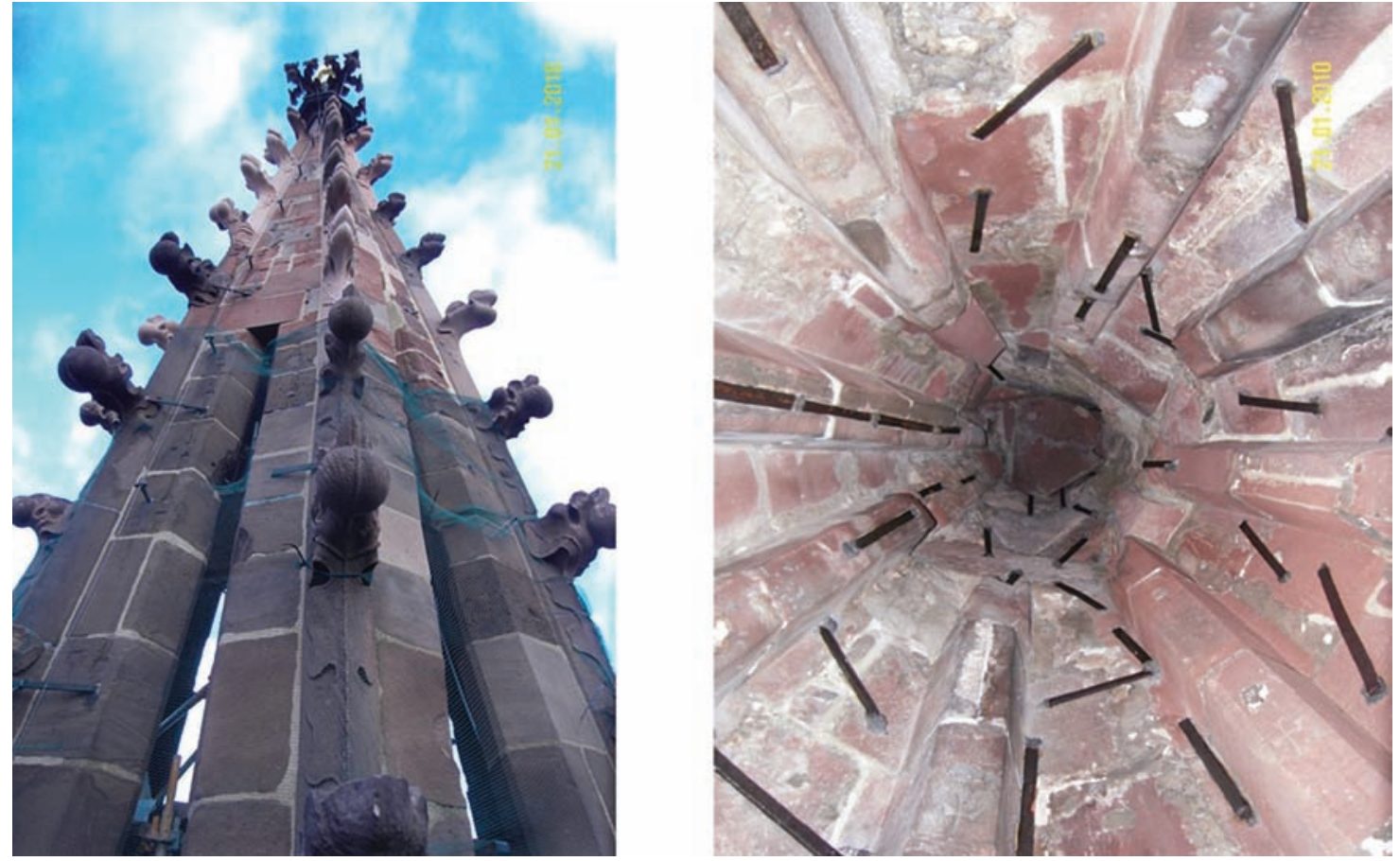

Figure 5. Views of the pinnacle from outside (left) and inside (right)

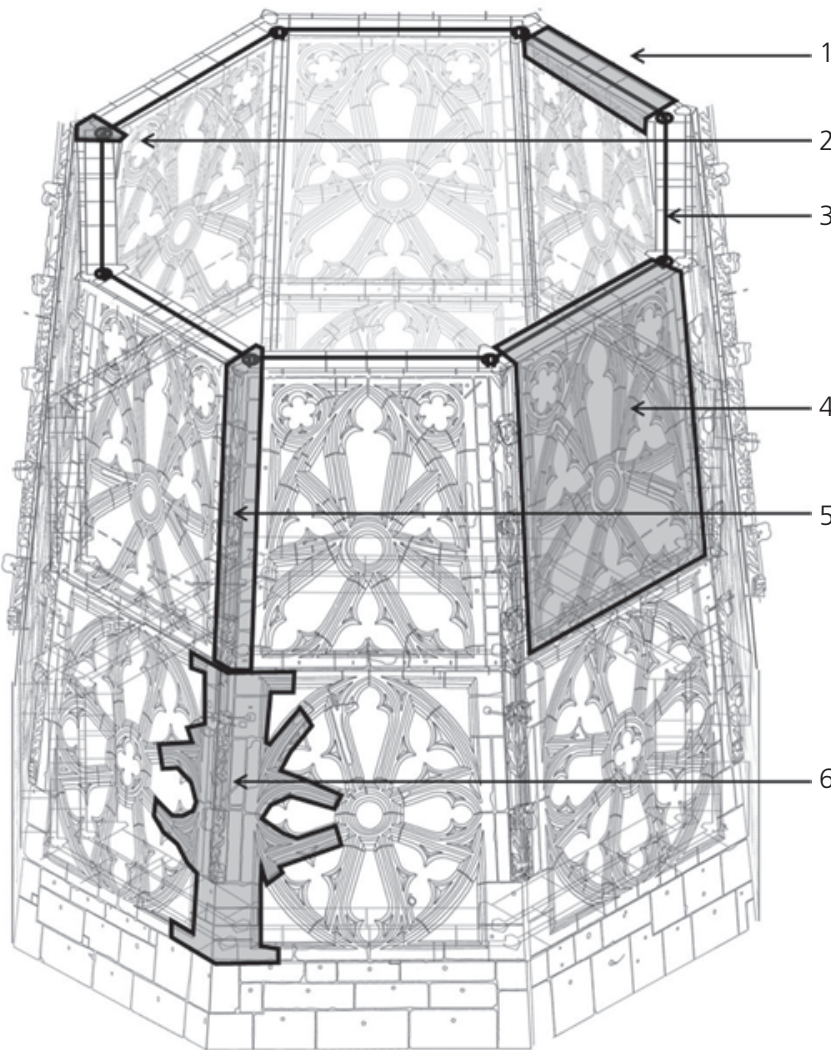

Figure 6. Nomenclature of construction elements: 1, chord; 2, cornerstone; 3, iron tie; 4, tracery panel; 5, strut; 6, interlocking of strut and tracery at the first storey dangerous to remove one without providing appropriate bracing and temporary support.

Another type of damage occurs in the stones of the chords. Many show vertical cracks starting from the channel cut to contain the tie. Some of these cracks split the stone into two pieces, while others end somewhere inside the stone.

The initial assumption was that the corrosion of the iron ties was the reason for the cracks. And, indeed, in some chords with dimensions of $100-200 \mathrm{~cm}$, significant corrosion of the ties was found. The thickness of the corrosion product is up to $8 \mathrm{~mm}$, making it clear that the stone had to crack at those locations. Water had infiltrated through open joints between the coping stones and was trapped in the tie channel. It is likely that during the last 700 years there were long periods of time in which the tower was in bad condition and not well maintained. Joints may have been open for a long time. Thus, water freezing also could cause damage.

However, the corrosion of the iron ties does not sufficiently explain all the cracks and defects. Corrosion was found only in a few areas, and these areas do not always coincide with the areas of major damage. Elsewhere there is virtually no corrosion. At the cornerstones in particular, where the iron was very well protected by the stone above, there is absolutely no evidence of corrosion.

Generally speaking, inside the tracery the damage was not found to be alarming. There is little more than a few displacements and minor spalling at some joints (Figure 10). Fortunately, only a 


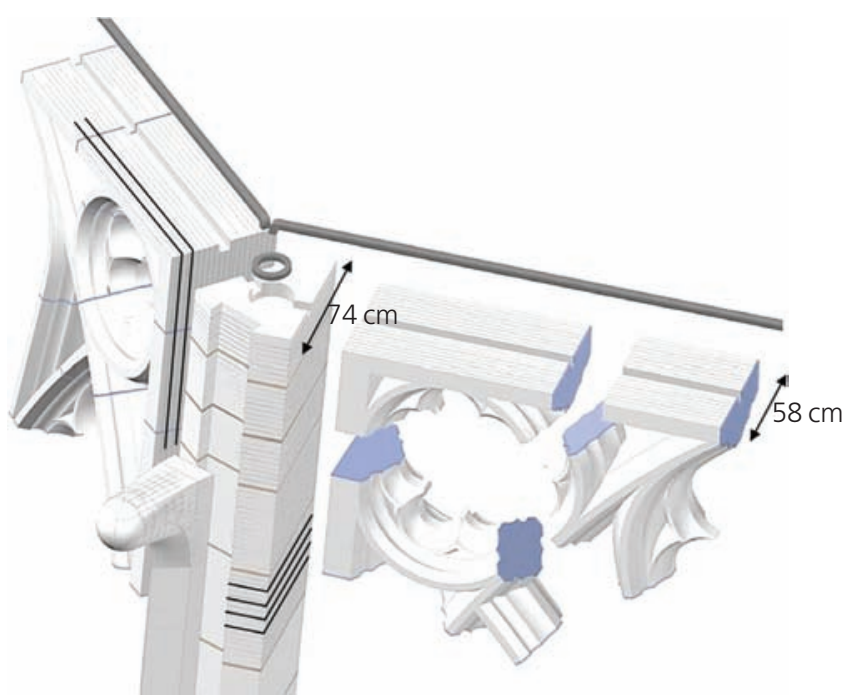

Figure 7. Exploded isometry of stereotomy at the corners

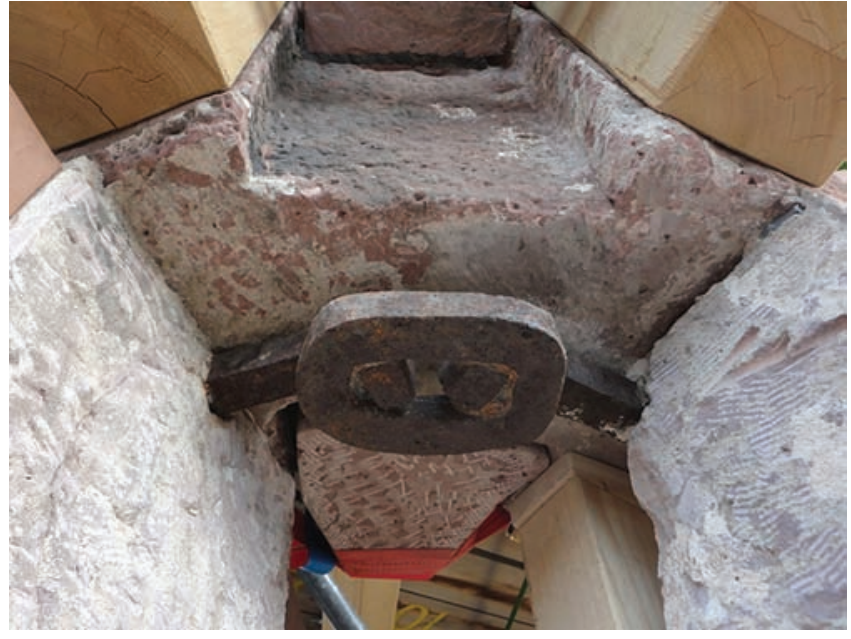

Figure 8. Underside view of iron tie and ring during replacement of cornerstone, level 8, south-south-east strut
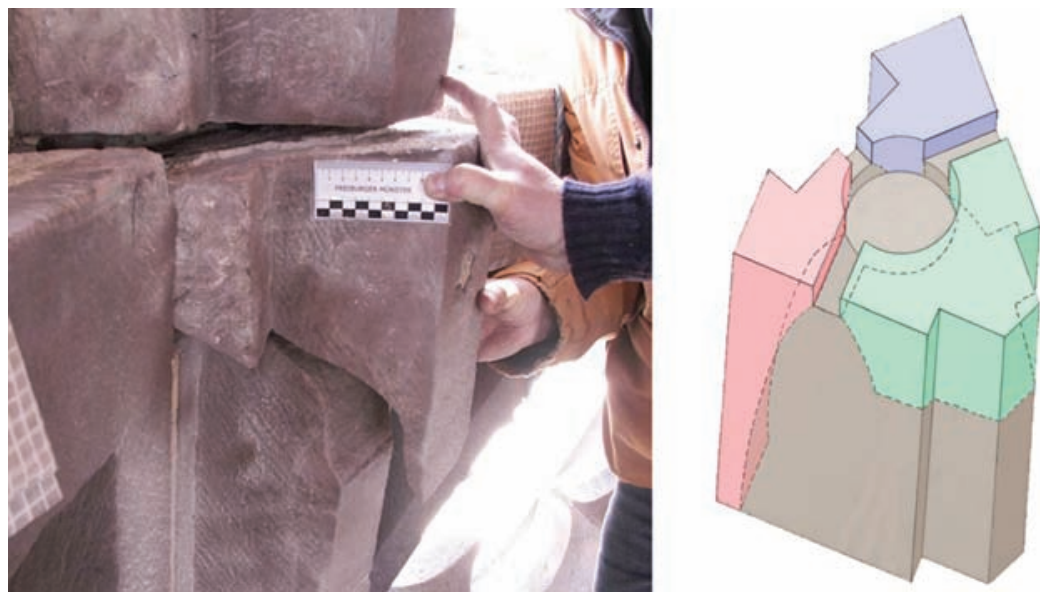

Figure 9. Wedge-shaped fragment of a cornerstone, level 5, east-north-east strut (Freiburger Münsterbauverein e.V.)

small number of stones had developed cracks parallel to the outer surface of the tracery panel, which would be dangerous. While there are some cracks that seem to be due to tensile stresses, more often the cracks indicate bending (Figure 10(b)). Depending on the design of the individual tracery elements, they are very sensitive to imposed deformations. In most cases the latter occur due to a slight widening of the horizontal span between the struts. A widening of only a few millimetres causes displacements inside the tracery, which can lead to bending cracks in the filigree stone elements. The cause of this widening is not quite clear. It might have occurred shortly after erection due to elastic displacements and a general consolidation of the structure, or it might be caused by damage in the cornerstones where the iron ties are anchored.

All the visible damage and deformations were recorded. Especially important was the need to identify the repair measures carried out in former repair campaigns. Substantial repairs were undertaken in the sixteenth century, in the nineteenth century, in 1920 and again in 1963. The quality of these measures differs greatly. For example, the sandstone used in the 1960s was of very poor quality. The weathering of this new stone was very severe compared with that of the original stone, and nearly all of it had to be removed and replaced by a more robust stone. The original stone shows hardly any weathering due to either mechanical or organic agents.

During this investigation work, it was found that two-dimensional (2D) records were not sufficient to show full details of the condition of each stone, the mortar and the iron ties. Originally, the struts and the tracery consisted of one layer of stones. In the past, damage and severe cracks had not always been repaired by replacing whole stones. Very often only a part of a large stone 
Engineering History and Heritage

Volume 169 Issue EH2
The Gothic tower of Freiburg Minster,

Germany: analysis and repair

Barthel, Tutsch and Jordan

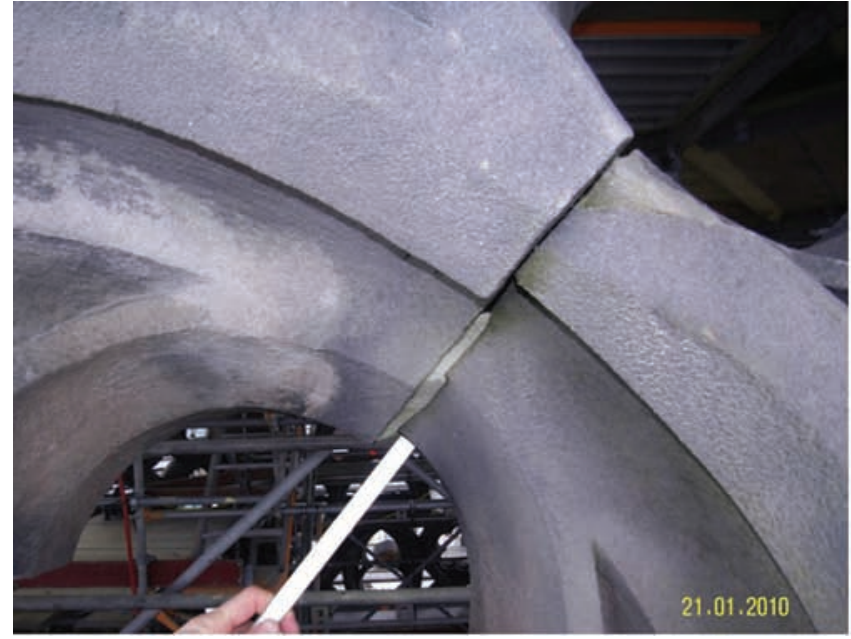

(a)

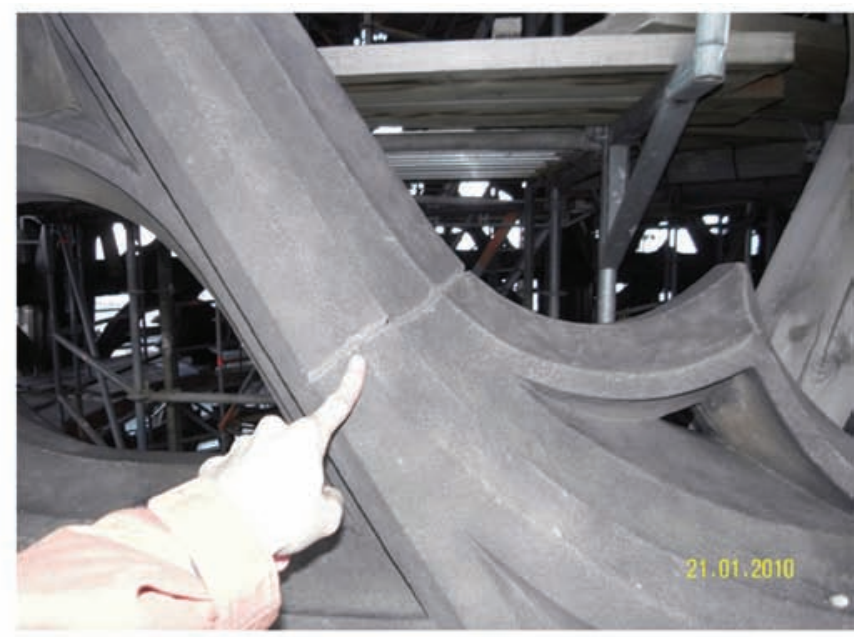

(b)

Figure 10. Typical damage inside the tracery: (a) relative displacement; (b) bending crack

had been removed and replaced with several smaller pieces. In some areas, particularly in the chords, the present construction has a three-dimensional (3D) pattern: damage at the outer face and damage on the inner face are not identical. Using only 2D drawings, such complexity could not be recorded sufficiently accurately to avoid confusion and to ensure a full understanding of the situation.

It was decided to build a full $3 \mathrm{D}$ computer model of the entire structure. Every stone, every joint and every metal piece is modelled as a separate element; every crack and other anomalies are fully modelled too. All historical alterations are also included. The model was created using a photogrammetric survey, which was completed by hand measurements.

By using this model, many different ways of visualising the structure are possible (Figures 11-13). It also becomes much easier to detect areas that are not stable due to damage or earlier, unsatisfactory repair measures. Figure 11 illustrates the current geometry of a single chord stone that had fractured and been repaired by using several small pieces of stone. The splitting is seen to penetrate deep into the tracery. With the awareness that heavy loads from above have to be supported by this element, it is essential to understand the true geometry of the stones in the structure.

The computer model provides a complete documentation of the present state of the spire. The model is linked to a data bank in which all hand drawings, photographs and written comments are filed (Barthel et al., 2014).

\section{Structural analysis}

Several different methods of modelling the structure were tested in order to find an appropriate way to conduct structural analysis calculations. The first approach was a finite-element model using simple plate elements for the tracery panels with a reduced stiffness. A more complex model was also created consisting of beam elements and special gap elements at the joints in the tracery with separate truss elements for the iron ties (Figure 14). This model is very cumbersome, and the results are not easy to check; numerous iteration steps are necessary, especially under wind load, and evaluating the results is both complex and time consuming.

Therefore, a much simpler model was also developed to gain a better understanding of the overall statical behaviour. The tracery panels are substituted by simple truss elements, and their stiffness was derived from a detailed analysis of the various types of tracery under vertical and lateral shear forces. The truss elements can transfer only compressive stress; in addition, the stress-strain relation in compression is non-linear.

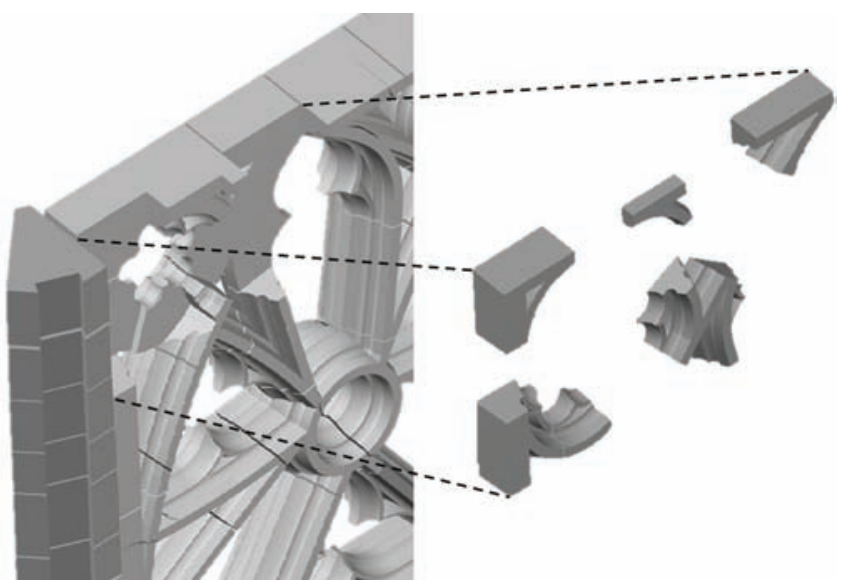

Figure 11. Exploded isometry of heavy fragmented tracery, storey 2 

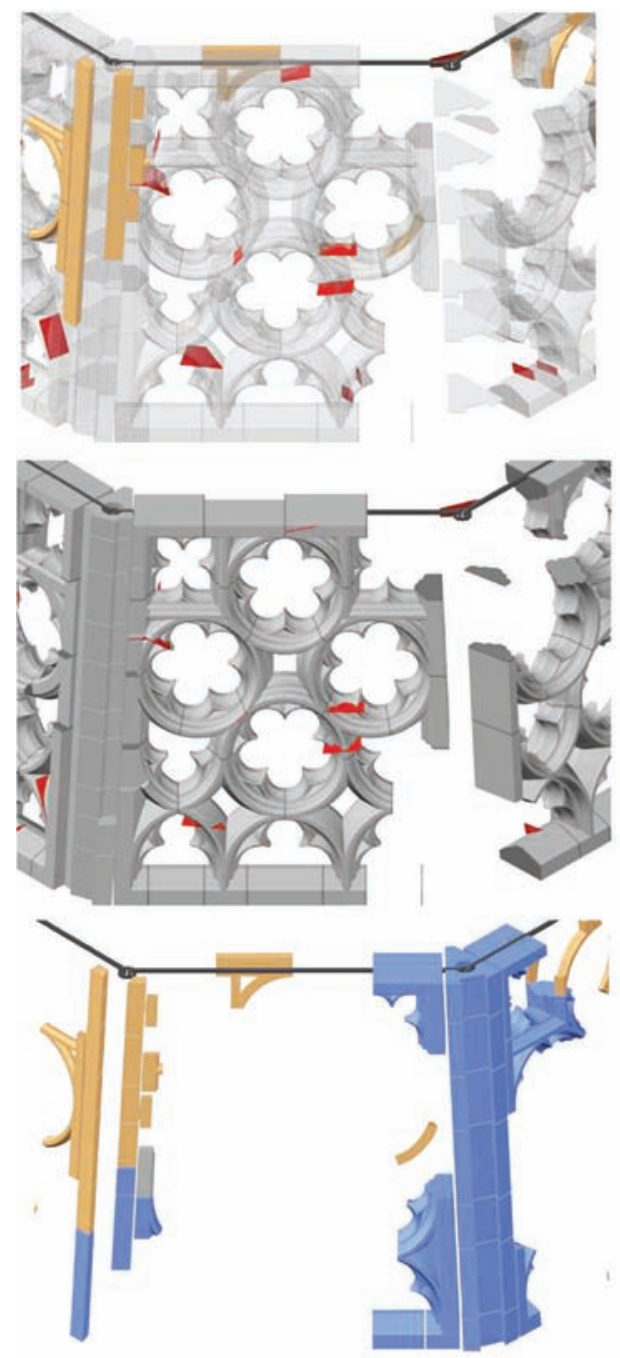

Initially, the ideal geometry of an octahedral pyramid was taken as a basis. Later, the models were modified to correspond to the real geometry of the spire, which is an asymmetric octagon in plan and includes kinks and other irregularities in the struts. Numerous individual structural details were analysed by means of finite-element calculations.

\subsection{Dead load}

The total weight of the spire is $6310 \mathrm{kN}$. For comparison, the total weight would be $9470 \mathrm{kN}$ if the structure were of the same thickness but with solid masonry walls. The 3D model of the spire turned out to be very useful even for the statical calculations. Previous calculations had used values for the selfweight based on very rough estimates, with some weights twice as large as in reality.

The tracery panels are not only ornamental - they support the weight of the entire structure above. The load paths through the tracery panels result in a concentration of forces along the vertical edges. This is largely because the vertical elements along the edge provide the stiffest route compared with the infill panels and thus attract the largest loads. Because there is no interlocking of the panels with the struts, the loads cannot be transferred from the struts to the panels - or rather only to the extent of the friction between these two elements along the joint.

The pattern of the tracery causes horizontal forces that provoke a certain increase in the circumference of the octagon. On the other hand, the overall shape of a pyramid gives rise to horizontal compressive forces, which hold the structure together. The resultant tensile forces in the wrought-iron ties therefore remain small.

One feature of the construction is particularly surprising. The only structural elements connecting the tracery panels with the struts are the iron ties. However, the struts and the tracery panels do not have the same stiffness in the vertical direction. Different displacements due to elastic deformation or shrinkage can thus 
Engineering History and Heritage Volume 169 Issue EH2
The Gothic tower of Freiburg Minster,

Germany: analysis and repair

Barthel, Tutsch and Jordan

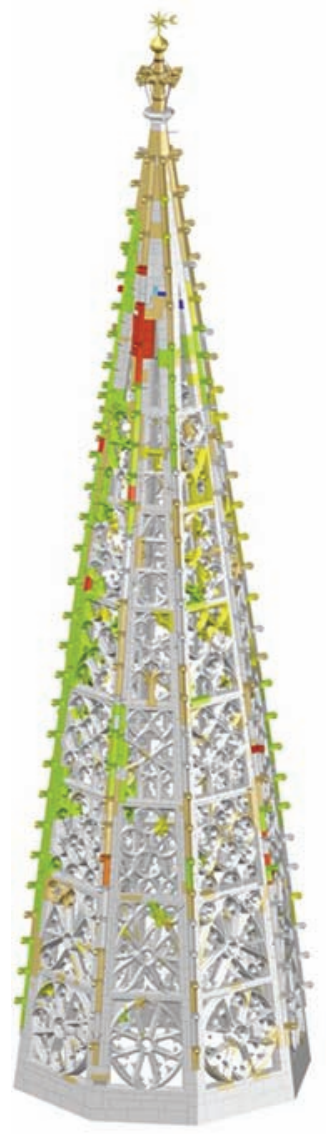

(a)

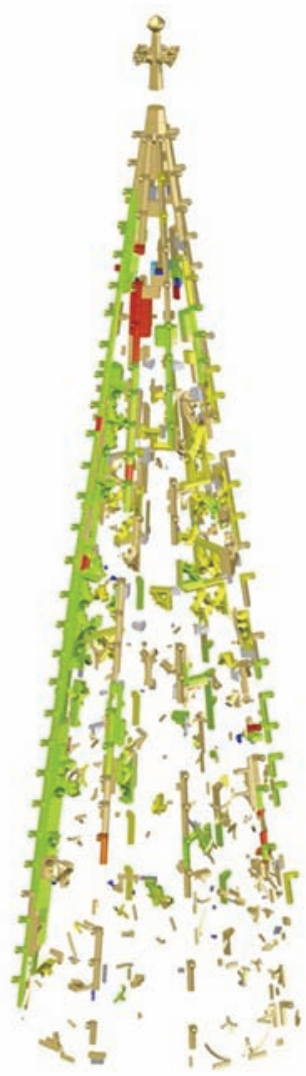

(b)

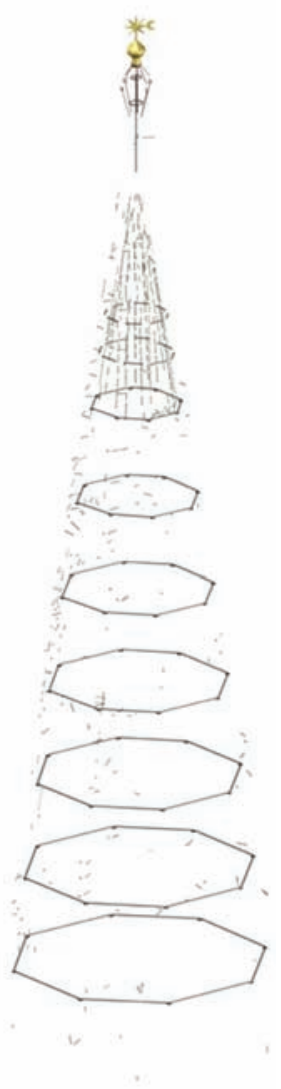

(c)

Figure 13. (a) Complete structure; (b) replaced stones; (c) iron elements

cause significant shear forces in the ties and the adjacent stones. The tie becomes a 'shear pin', which can give rise to local stress peaks and tensile stresses in the stones. This may well account for the vertical splitting of numerous stones in the horizontal chords adjacent to the struts. This effect would have occurred shortly after the original erection, and the initial damage may thus have occurred when the structure was still very young.

\subsection{Wind load}

Since there is no information on assumptions regarding wind loads on such a structure, wind tunnel tests were conducted on a physical model. Wacker Engineers, who are experienced specialists in that field, were commissioned to undertake experiments on a 1:100 scale model of the entire octagonal tower and spire. Using this $60-\mathrm{cm}$ model, the resulting wind forces at each level were determined. Further models at 1:40 scale were made of smaller sections to determine the distribution of forces around the circumference of the spire. Both models were manufactured by 3D printing (Figure 15). A peak-velocity wind load of $1.21 \mathrm{kN} / \mathrm{m}^{2}$ is assumed, which corresponds to a velocity of around $44 \mathrm{~m} / \mathrm{s}$ with a 50 -year return period.
The resultant wind force on the structure is astonishingly large: indeed, the force is much higher than on a spire which is not perforated. The wind force corresponds to a force coefficient of roughly $1 \cdot 4$. A review of literature on wind on a completely closed octagonal spire - with no tracery - revealed typical force coefficients between 0.6 and 1.0 (Gerhardt et al., 2013; Szalay, 1983).

The resultant forces due to the wind acting on each tracery panel were determined. Each force consists of two components: a component perpendicular to the surface and a component parallel to the surface. The forces acting parallel to the surface are particularly high due to the roughness of the surface. The suction forces on the structure are relatively small.

The forces in the ties and the fixings where they are embedded in the masonry are much larger than under self-weight only (Figure 16). At the fixings the maximum tensile force is $226 \mathrm{kN}$, nearly three times that under self-weight. The maximum tensile force in the upper ties is $65 \mathrm{kN}$. To assess the role of the ties when wind loads are imposed, the upper ties were omitted from the statical model. The model was rerun and it was found that the iteration 


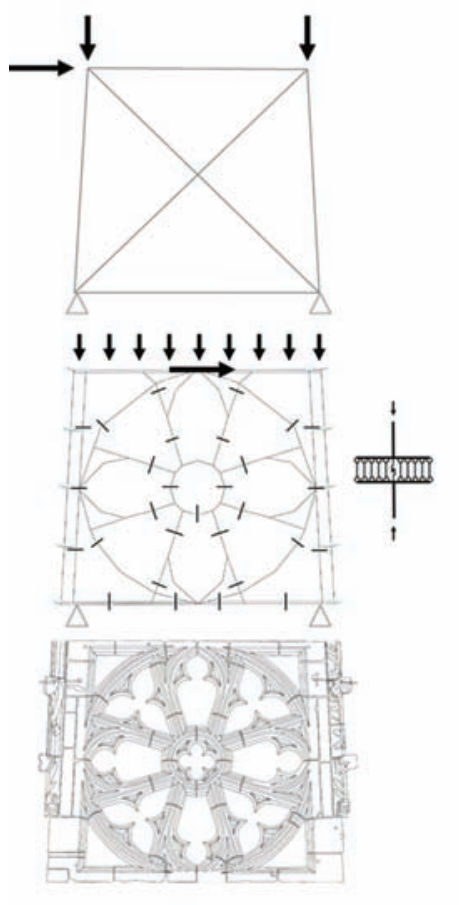

(a)

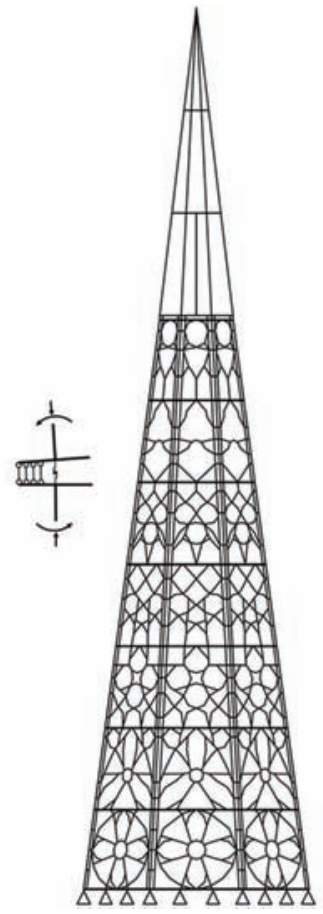

(b)

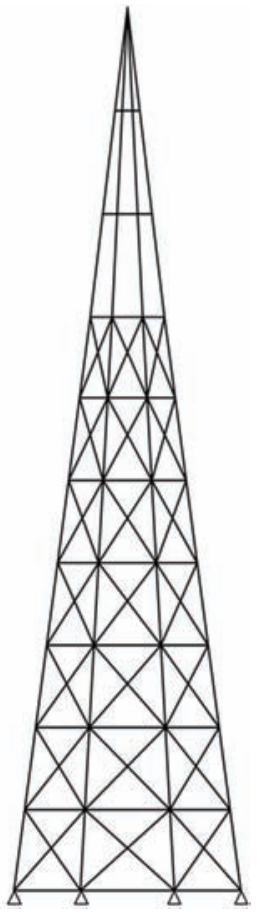

(c)

Figure 14. Static modelling: (a) modelling aspects of geometry and stiffness; (b) complex model with non-linear joints;

(c) simplified model with non-linear diagonals

did not reach an equilibrium state, demonstrating that the ties are indispensable for the overall stability of the spire.

The tracery panels parallel to the wind direction act as shear walls (Figure 17). At the cornerstones two effects occur: the forces in the ties have to be diverted, causing forces inwards, and, secondly, a proportion of the forces have to be anchored in the stone. Both effects lead to tensile stress across the full thickness of the stones (Figures 18(a) and 18(b)).

Along the chords, bending moments were found to occur due to the local wind load. The chords also develop flat-arch action (Figure 18(c)). This causes additional tensile forces, which, in turn, also have to be carried by the ties. This flat-arch action is possible only if the stones of the chord and the ties are stiff enough. Otherwise, the tie itself acts as a beam element. Both cases generate tensile stress inside the cornerstones (Figures 18(c) and $18(d))$.

\subsection{Seismic load}

Vibration measurements were conducted on the model and determined that the vibration period of the first and second eigenform is around $60 \mathrm{cycles} / \mathrm{min}(1 \mathrm{~Hz})$. The corresponding deformation was found to correspond to what would be expected for a cantilever with a cross-section consisting of a relatively 'soft' octagonal core. The spire is relatively stiff. Assuming the seismic zone and the foundation behaviour according to eurocode 8 , the equivalent static lateral seismic load was found to be higher than the total wind load. A storey-by-storey or even stone-bystone assessment of the effects of this load within the statical model is currently being implemented.

\section{Material tests}

A great number of material tests were undertaken. The mechanical properties of the original and new mortars, the lead, the sandstone and the wrought iron were determined. In addition, some full-size copies of structural elements were tested in the laboratory. Some non-destructive testing was also undertaken to investigate internal cracks in the stone.

One result of fundamental importance was revealed by this series of tests: it was found that the coefficient of thermal expansion of the historical sandstone and that of the wrought iron is the same, indicating that these two materials fit together very well.

The interaction between the ties and the cornerstones, especially the behaviour of the sandstone, was tested using a full-size model (Figure 19). In the model the ties consisted of modern steel; separate tests examined the behaviour of the historical wrought iron.

The tests were conducted to investigate every relevant combination of vertical load and tensile force in the ties. Due to 
Engineering History and Heritage

Volume 169 Issue EH2
The Gothic tower of Freiburg Minster,

Germany: analysis and repair

Barthel, Tutsch and Jordan

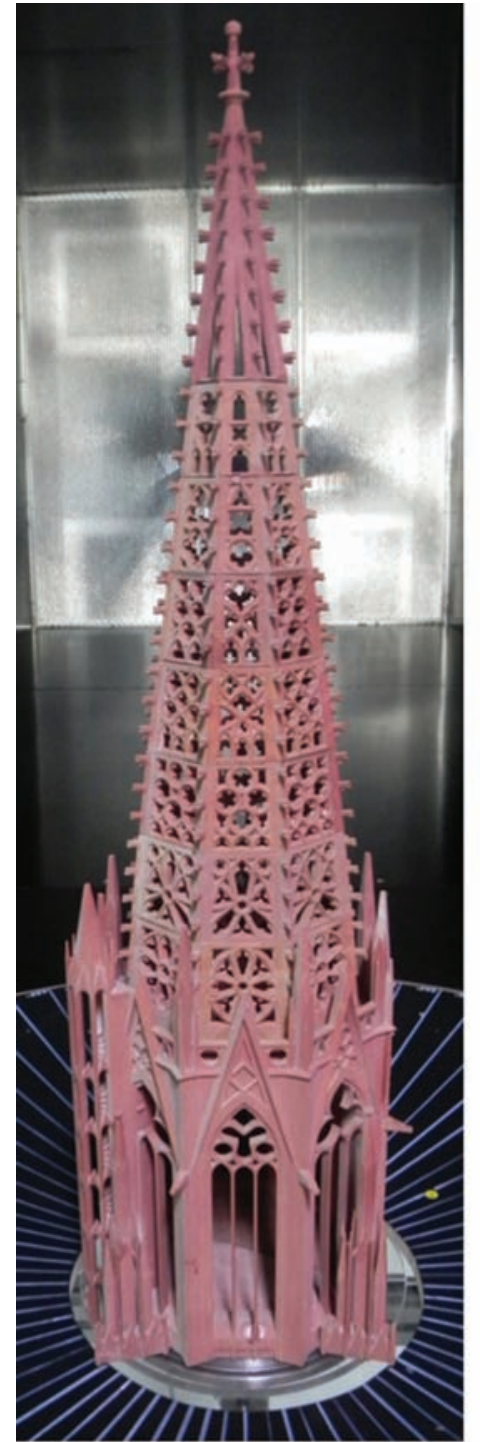

(a)

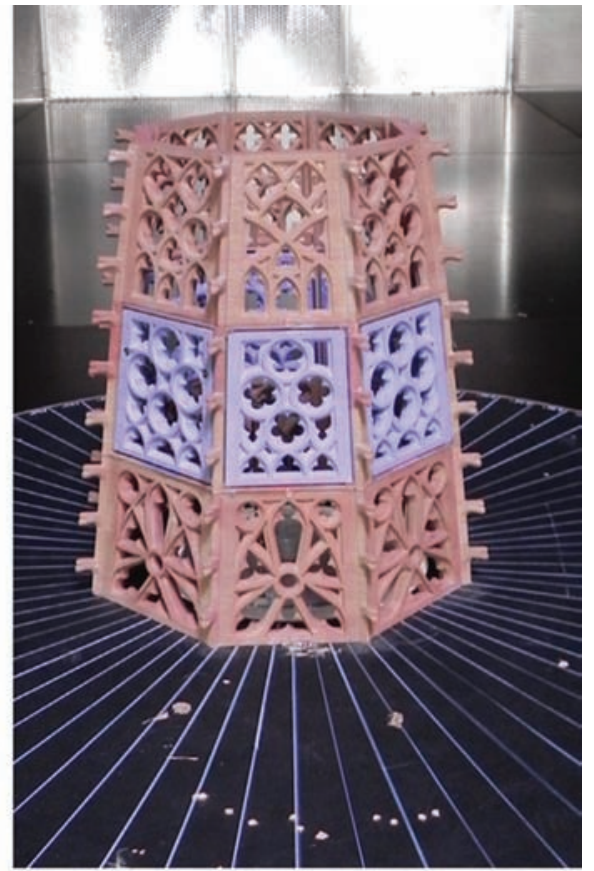

(b)

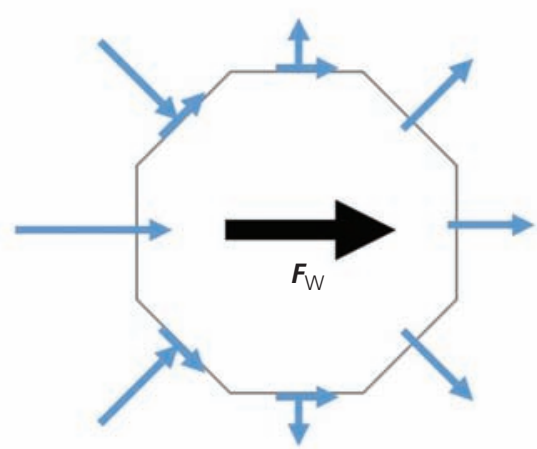

(c)

Figure 15. Wind tunnel tests: (a) model of spire, scale 1:100; (b) section model of storeys $2-4$, scale 1:40;

(c) wind forces perpendicular/parallel on each surface and resultant force

the tensile force in the ties, shear stresses occur inside the sandstone. The failure load essentially depends on the size of the vertical load, which consists of dead load plus a component due to overturning by the wind. Considering such a vertical load, the sandstone fails due to a tensile force in the ties, which is up to five times as high as required according to the statical calculations (Figure 19(a)). The failure mode is more or less the same as was detected in the original cornerstones of the spire (Figure 9).

A modified test set-up enabled the flat-arch action in the chords also to be simulated. This test proved not only that the failure forces were relatively large but also that the failure mode is realistic (Figure 19(b)).
The results of these tests have to be handled with care, however. The failure mode is an important confirmation of the principal structural behaviour, but the measured magnitudes of the maximum failure load are more or less theoretical. The full-size model built in the laboratory represents an ideal situation: the iron is embedded completely in lead. In order to avoid stress concentrations, there is no direct contact between the iron and the stone. In order to avoid notch stress concentrations in the stone, the corner radius was precisely defined and implemented. In the tower, all this was done in a cruder manner, and many accidental effects may have a great influence on the bearing capacity of the original stone. Nevertheless, the test results show that the cause of damage in the stone is principally not due to overloading, 


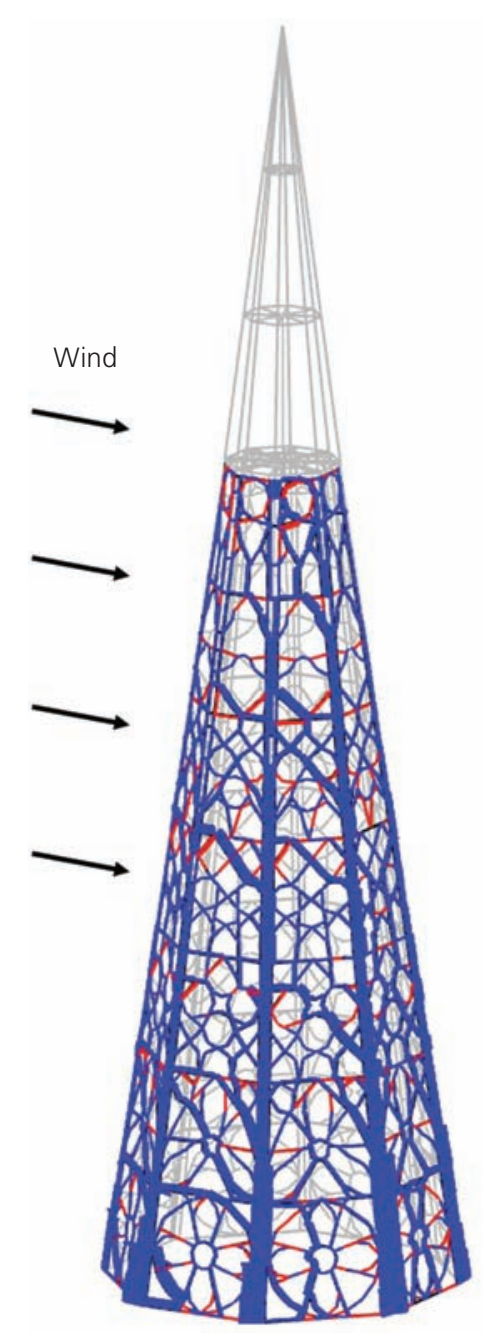

(a)

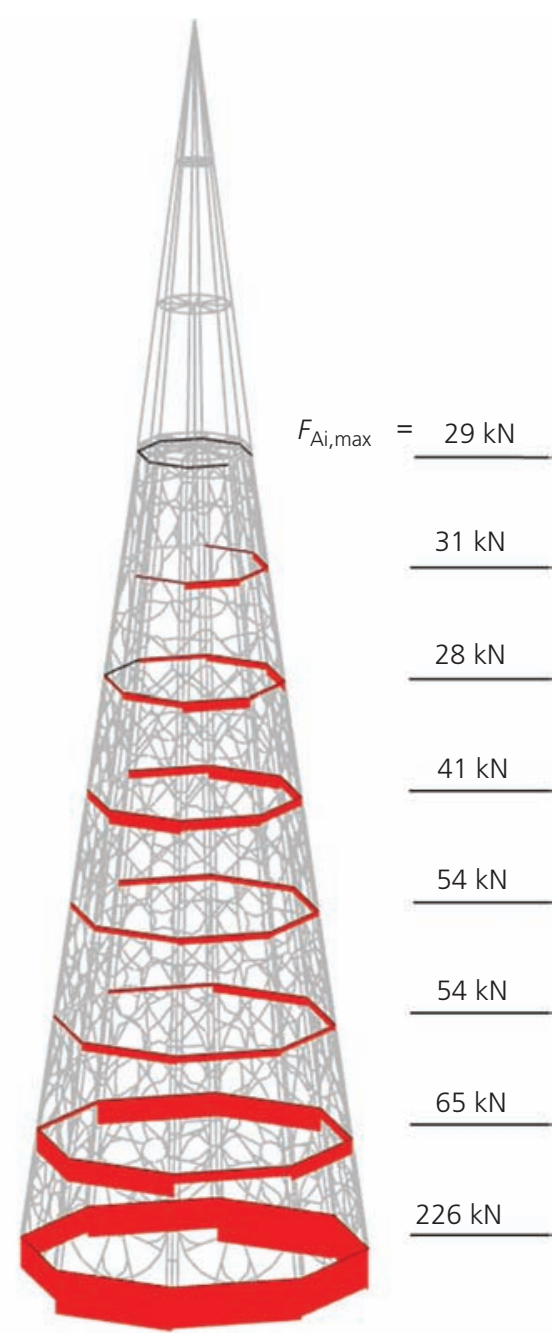

(b)

Figure 16. Distribution of wind loads: (a) compression forces (stones); (b) tension forces (iron ties)

but rather due to stress concentrations arising from local imperfections and defects, or due to weak sediment layers or other localised characteristics.

From the start of the investigations, the question was raised as to whether it would be possible to use non-destructive methods such as radar and ultrasound to detect internal cracks in the stone. However, that is difficult because of the complex geometry of the stones and the presence of lead and iron. The full-scale models in the laboratory were used to evaluate the reliability of these methods. On site, however, it was found that it was not feasible to achieve reliable results with either radar or ultrasound.

It was considered important to test the properties of the wroughtiron ties using authentic elements. While it was not possible to take ties out of the structure of Freiburg Minster, a number of historical ties were available from a similar structure of the same century and also from elsewhere in the Minster. In the 1960s the small towers in the choir of the minster were dismantled and reconstructed with new material. The original ties were kept in the museum. It was judged realistic to assume that the material and its manufacture would be similar enough to those in the spire to yield useful and reliable results. The ties and the hooks were tested under tension and bending.

The results of the tensile tests vary. There were samples showing a very high tensile strength, with a failure stress of up to $400 \mathrm{~N} / \mathrm{mm}^{2}$. Also, the ductility was surprisingly high. But there were also samples which were rather weak due to slag inclusion.

After removing one damaged cornerstone, a crack in the hook end of the tie became visible. It looked like a brittle crack. The decision was made to test the hook under realistic circumstances. A test model was constructed simulating the constraint provided by the geometrical restriction and the lead. Again, the historical hooks from the small tower were used. 


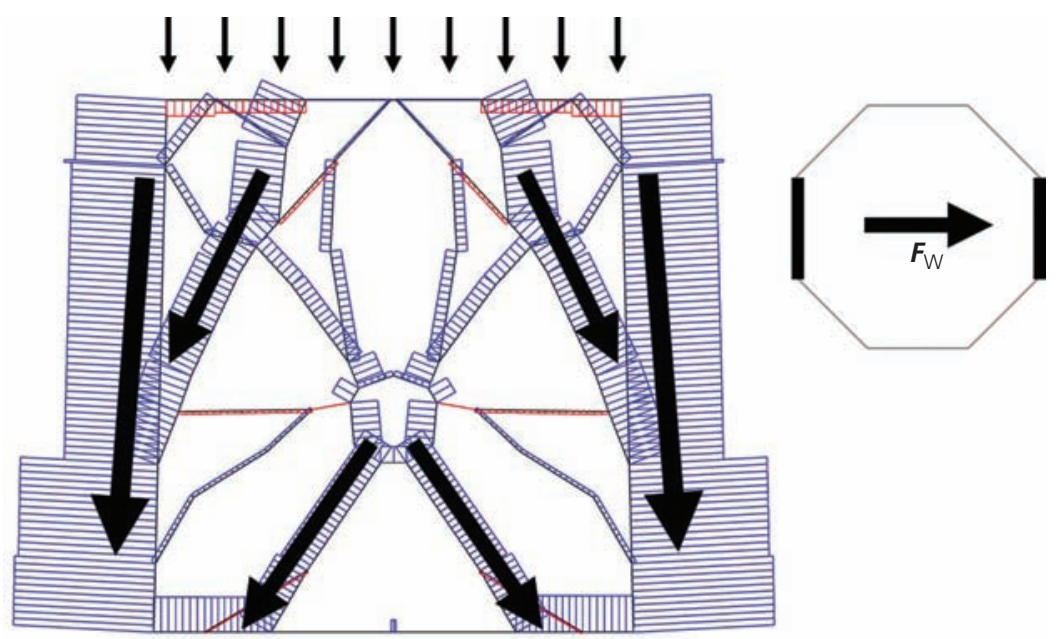

(a)

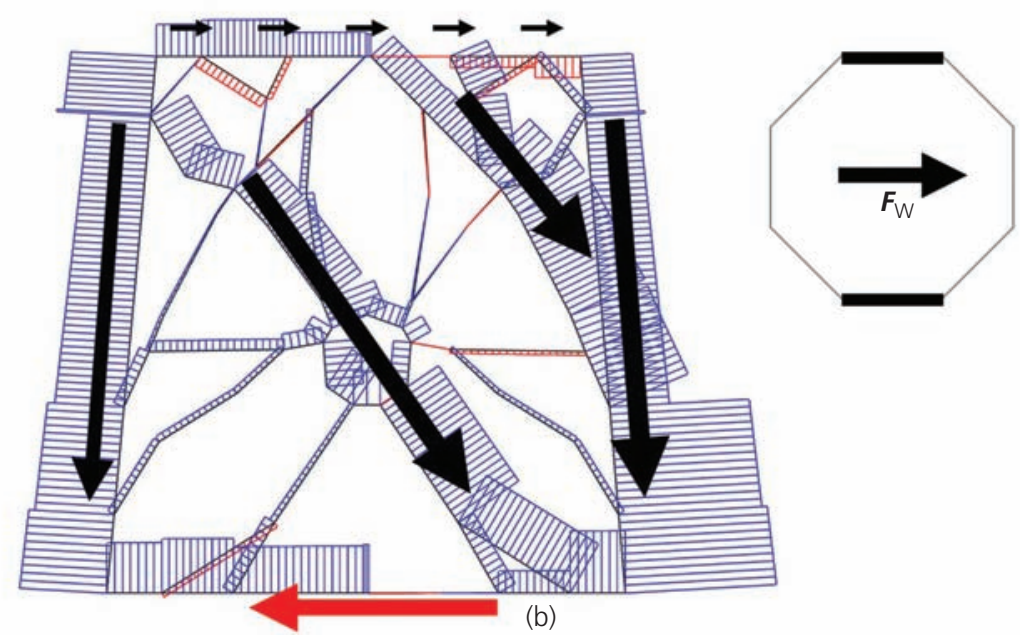

Figure 17. Distribution of wind loads exemplified on second storey: (a) perpendicular to wind direction (compression);

(b) parallel to wind direction (shear)

Only one sample showed a maximum tensile strength of over $100 \mathrm{kN}$. The maximum strength of other samples was only half or two-thirds of this value. The failure plane of these samples showed a slightly corroded area, indicating an initial fracture. This fracture was exactly at the turn of the hook. From the outside these fractures were not detectible. After testing, it was possible to get similar values for the failure load by theoretical calculation, taking into account the reduction of the cross-section due to corrosion and assuming a tensile strength of $400 \mathrm{~N} / \mathrm{mm}^{2}$.

The explanation for this weakness probably lies in the process of manufacture. It is not easy to forge such a hook. A convenient method would be to take some material out of the bar, bend it and then forge it together again. Sometimes the blacksmith succeeded in producing a good forge weld, but sometimes he did not.
The problem is that it could not be checked. From the outside, it is not possible to see whether there is still a hidden gap or an incomplete joining of the pieces of iron.

It thus became necessary to consider whether the ties and the hooks are less reliable than first assumed. The ties from the small towers may be of a different quality from the ties of the main tower. Therefore, further investigations and tests are being undertaken in order to reach a realistic assessment of the ties and hooks in the main spire.

It is interesting to find that the forces and the load-bearing capacity of the materials are more or less the same. The tower has already survived 700 years. The master builder must have had a good feeling for the loads and the resistance of the materials and 
Engineering History and Heritage Volume 169 Issue EH2
The Gothic tower of Freiburg Minster,

Germany: analysis and repair

Barthel, Tutsch and Jordan
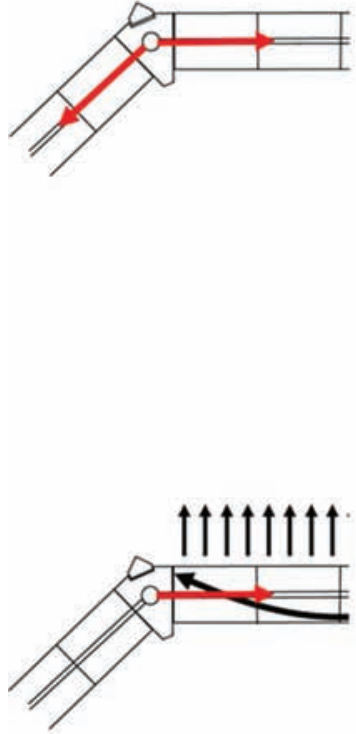

(c)

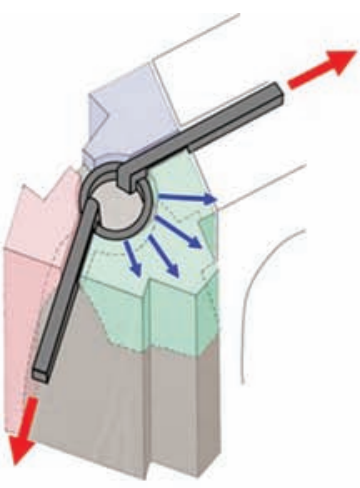

(a)
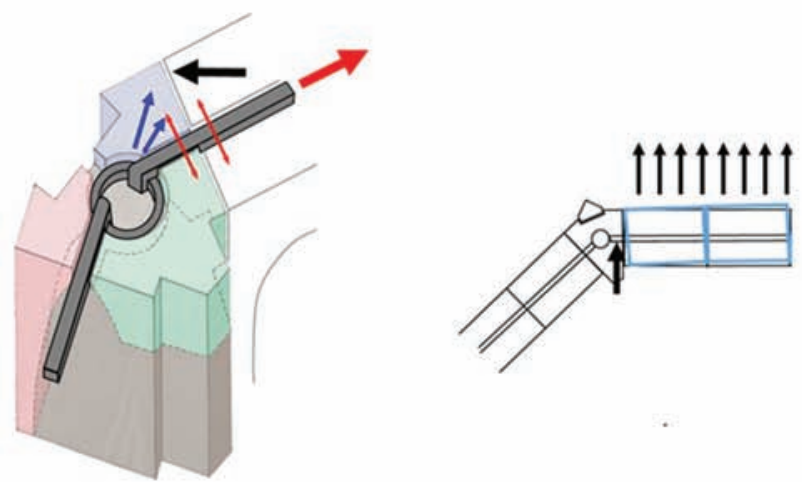

(d)

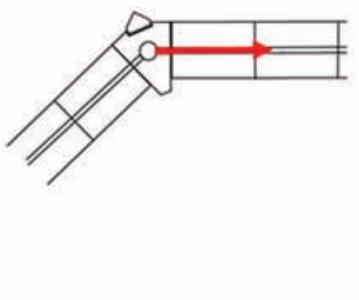

(b)
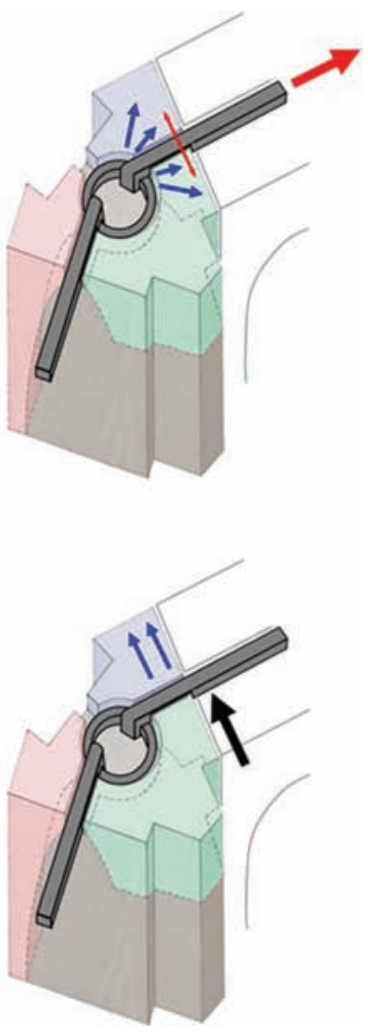

Figure 18. Distribution of acting forces at cornerstones:

(a) diverted tension - inward forces; (b) anchored tension - lateral tension inside the stone; (c) flat arches - additional lateral tension;

(d) slack chord stones - iron tie as shear pin

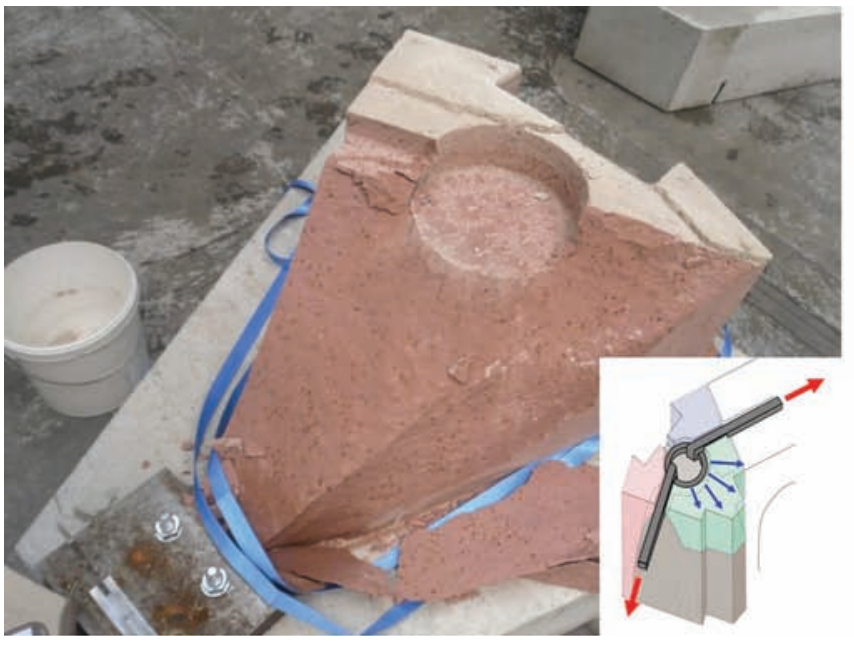

(a)

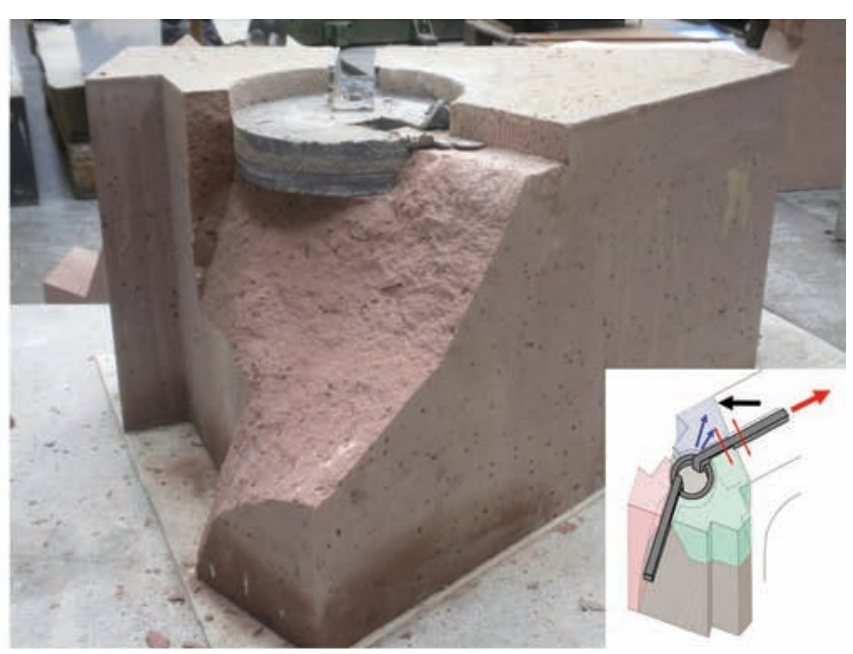

(b)

Figure 19. Testing model, scale 1:1: (a) failure mode of diverted tension; (b) failure mode of flat-arch action 
Engineering History and Heritage

Volume 169 Issue EH2
The Gothic tower of Freiburg Minster,

Germany: analysis and repair

Barthel, Tutsch and Jordan
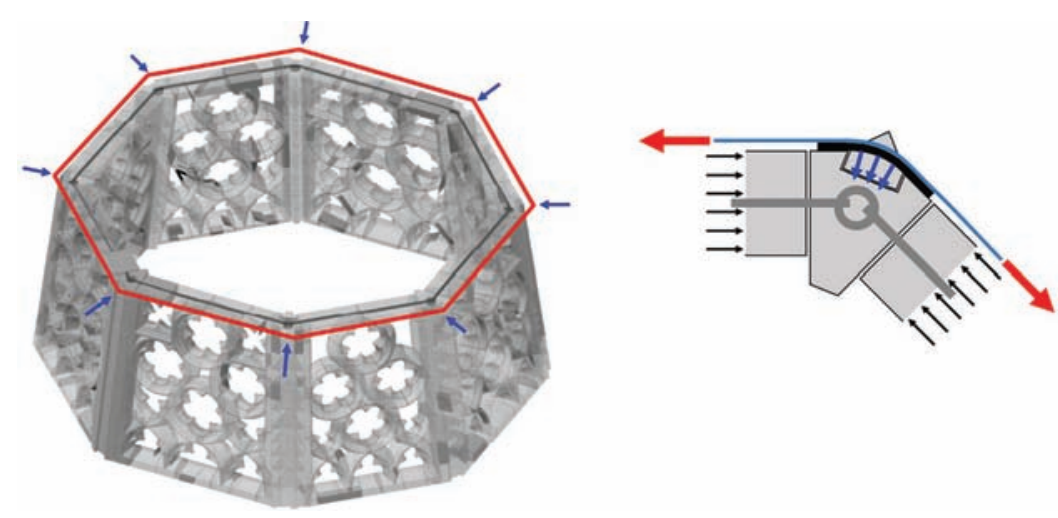

Figure 20. Functional principle of repair concept A: pre-tensioned, external titanium cables

the building as a whole. However, contemporary understanding of safety is more demanding than that of the Middle Ages.

\section{Repair}

Two repair philosophies were discussed. The first proposed using external ties or even steel cables to embrace the whole structure horizontally (Figure 20). These ties are positioned on the outside of the structure at the level of the chords and post-tensioned to eliminate the tension forces in the original ties. No drilling is required. At the cornerstones, steel brackets are required to take the forces. The cornerstones are thus loaded in 3D compressive stress. This ensures that the repair of the damaged cornerstones is easier and more of the original cornerstones can be kept. The chords are also loaded in compression, which assists the flat-arch action under local wind loading.

This repair philosophy aimed for the minimum of interventions and alteration to the historical structure. However, this solution would generate entirely new load paths inside the chords due to the post-tensioning. In statical terms this would be a major change; it could cause further unpredictable displacements and even damage, due to the inhomogeneity of the structure arising from the numerous repair measures completed in the past.

A second philosophy was developed which maintains the original statical situation, and this is the approach now being implemented. The stones and the joints will be repaired locally and, if necessary, strengthened to meet the local requirements. Due to the detailed damage survey and documentation, it was possible to develop repair measures for each individual location. Twelve cornerstones show small cracks, and a frame made of titanium was designed to hold them together and to provide adequate safety under vertical and horizontal loads (Figure 21). Eight cornerstones are badly damaged and must be removed and replaced by new ones. Split stones located in one third of the horizontal chords have to be replaced in order to achieve sufficient shear stiffness - a precondition for the flat-arch action (Figure 22). Split stones inside the tracery, which can cause out- of-plane forces, have to be removed and replaced. All historical repairs that do not meet the statical requirements have to be replaced.

When implementing this kind of in-depth repair, it is possible to strengthen the overall structure and to increase substantially the robustness and level of security. However, if the original ties do
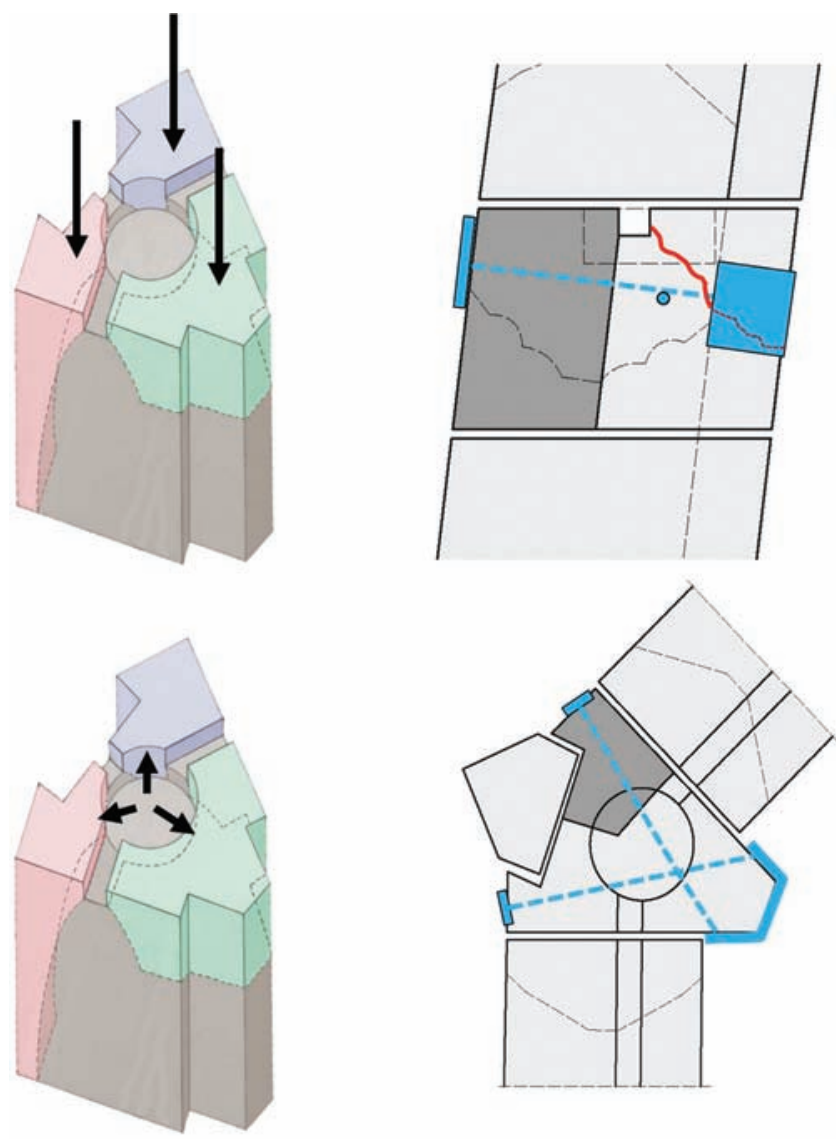

Figure 21. Functional principle of repair concept B: titanium clamp 

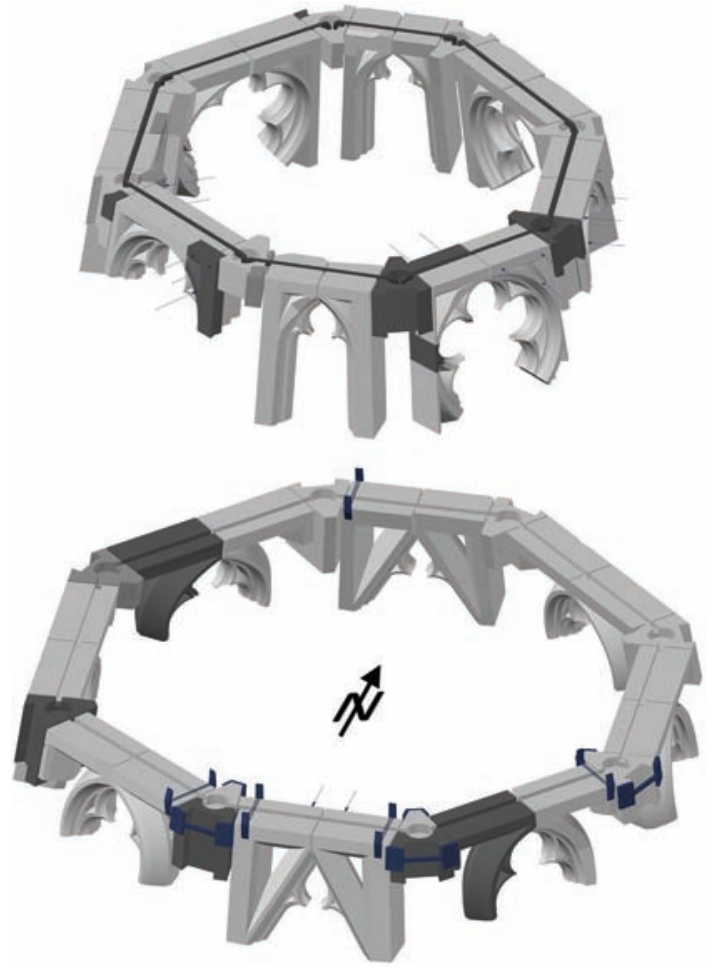

Figure 22. Repair plan: example for chords of storeys 6 and 7 (stone replacements are dark coloured)

not meet the required level of safety, additional ties are inevitable. The final decision depends on the investigations mentioned earlier, which still have to be executed. If additional ties are unavoidable, it is proposed that they are inserted at levels 3 and 5. The ties would consist of titanium with a diameter of $20 \mathrm{~mm}$. These ties are not post-tensioned or only to a small degree. The ties will thus not change the stress distribution and load paths in the original structure. The new ties would be stressed only if the original ties fail and significant displacements occur. It is sufficient to position the ties at only two levels because it is possible to prove that the failure of one original tie causes larger forces in the ties at the levels above and below. There is no danger if these forces can be so redistributed.

Two alternative ways of introducing these new ties are being considered. They could be positioned inside the upper part of the chords and anchored in the struts directly above the cornerstones. This would require drilling holes at least $35 \mathrm{~mm}$ in diameter over a length of about $5 \mathrm{~m}$. Alternatively, to minimise drilling, the ties could be positioned directly above the chords, necessitating penetration of three or four tracery stones. The diameter of the drilling hole could be reduced to $24 \mathrm{~mm}$. These ties would hardly be seen from below. Apart from being resistant to corrosion, a further advantage of titanium is that its Young's modulus is roughly half that of steel, which reduces the change in forces in the ties due to temperature variation. These additional ties will be inserted, if necessary, after the repair of all the stones.
The implementation of the various repair measures began in 2014 (Barthel and Tutsch, 2014). Due to the construction of the scaffolding, the work progresses from top to bottom. Currently the repair measures have been completed in the upper third of the spire. One of the remaining major challenges is the design of the temporary steel support structures that will allow the removal and replacement of several cornerstones (Figure 23).

\section{Conclusions}

The spire on the tower of Freiburg Minster is an invaluable monument of architectural and construction history. The analysis of the construction is an interdisciplinary research effort. Every detail is of high value in terms of art and technique. The tracery is a filigree masterpiece of medieval art, and at the same time it is a substantial structural element which must transfer both vertical and horizontal forces. Even the repair measures from the fifteenth and sixteenth centuries are witness to the level of technical development and understanding. Thus, it is worth assessing the construction to an extent which goes far beyond the normal in order to avoid repair or strengthening measures which alter the historical substance.

The tower has proved its stability for nearly 700 years. Such a statement is frequently used to justify the argument against undertaking any strengthening measures. However, 700 years do not prove that the tower is still safe or will continue to be safe in the future. The statical calculations and the tests show that the overall structure and the dimensions of the structural elements correlate more or less with the forces determined theoretically. However, the reliability of the numerous structural elements cannot be proved completely. Stress concentrations or a weak

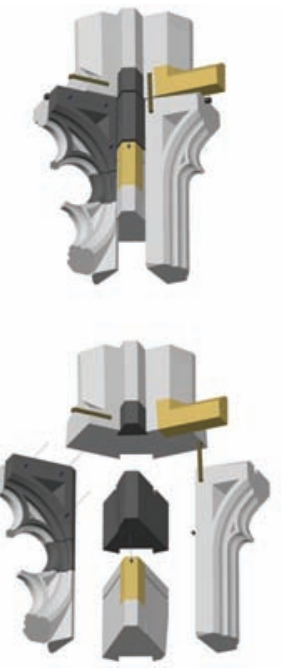

(a)

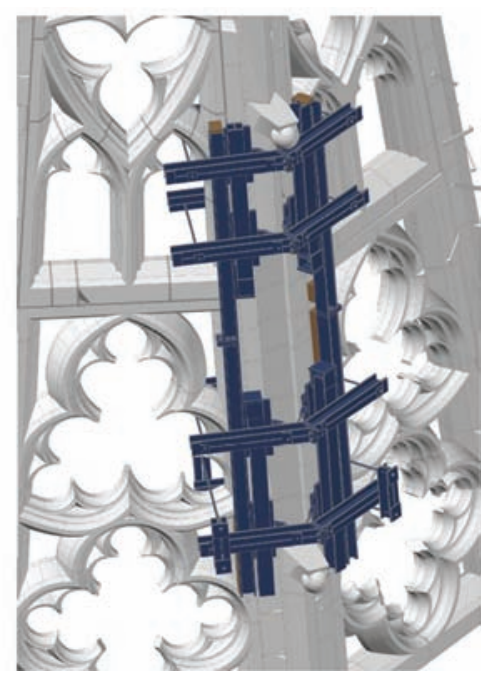

(b)
Figure 23. (a) 3D model of repaired stereotomy at certain corner; (b) 3D model of temporary steel construction for replacement of cornerstones 
Engineering History and Heritage

Volume 169 Issue EH2
The Gothic tower of Freiburg Minster,

Germany: analysis and repair

Barthel, Tutsch and Jordan sediment layer in the sandstone or slag inclusion in the wroughtiron ties cannot be excluded. In addition, the repair measures during previous centuries led to a much larger total number of stones and joints than in the original structure. That has weakened the structure and makes it impossible to assume the original level of safety. Even after repairing all the damage that was detected, it will not be possible to achieve the level of safety of the original structure. Thus, extreme wind loads or a large earthquake can be a real threat. It will not be possible to strengthen the structure to an extent that removes all the risks completely, according to the contemporary understanding of safety, without implementing major strengthening measures. This would destroy the original monument. The proposed strengthening by means of additional ties could reduce the risk of major damage or collapse substantially. The final decision on whether this is acceptable must be decided by consideration of the many and various values and points of view regarding historical structures.

\section{Acknowledgements}

The parties involved in the project are as follows

v client: Freiburger Münsterbauverein e.V., Yvonne Faller, Thomas M. Laubscher; Münsterbauhütte, Till Borsdorf, Luzius Kürten

- State Conservation Office: Landesamt für Denkmalpflege im Regierungsbezirk Stuttgart, Prof. Dr Michael Goer, Prof. Dr Bernhard Laule, Dr Dagmar Zimdars, Otto Wölbert and RolfDieter Blumer

- structural engineers: Barthel \& Maus GmbH; consulting engineers, Munich: Prof. Dr.-Ing. Rainer Barthel, Dr Joseph Jordan, Joram Tutsch, Dr Matthias Jagfeld, Dr Christian Kayser, Gabriele Aufinger, Jörg Rehm, Ivan Kovacevic and Frank Hölldobler

- proof engineer: Dr Ralf Egner

- further consulting engineers: Prof. Dr Fritz Wenzel, Karlsruhe; Guido Kremp, Freiburg; Stefan King

- wind tunnel measurements: Wacker Ingenieure, Birkenfeld

- vibration measurements: Ingenieurgruppe Bauen, Beratende Ingenieure, Karlsruhe
- material tests: Materialprüfungsanstalt Universität Stuttgart, Dr Joachim Kinder; Materialprüfungs- und Forschungsanstalt, Karlsruher Institut für Technologie, Karlsruhe, E. Kotan

non-destructive tests: GGU mbH, Karlsruhe.

\section{REFERENCES}

Barthel R, Kayser C, Jagfeld M and Tutsch J (2012) Bau-

konstruktive und statische Untersuchungen am Turmhelm des Freiburger Münsters. In Natursteinsanierung Stuttgart 2012 (Patitz G, Grasegger G and Wölbert O (eds)). Fraunhofer IRB Verlag, Stuttgart, Germany, pp. 137-157 (in German).

Barthel R and Tutsch J (2014) Instandsetzungskonzept für den Turmhelm des Freiburger Münsters - Schäden und statischkonstruktive Maßnahmen. In Der Turmhelm des Münsters Unserer Lieben Frau in Freiburg - Ein Bautechnikgeschichtliches Denkmal (Zimdars D and Wölbert O (eds)). Konrad Theiss Verlag, Darmstadt, Arbeitsheft 27 der Landesdenkmalpflege Baden-Württemberg, Esslingen, Germany, pp. 149-168 (in German).

Barthel R, Kayser C and Kovacevic I (2014) Pilotprojekt Freiburg 3D - Schadens- und Bestandsaufnahme. In Der Turmhelm des Münsters Unserer Lieben Frau in Freiburg - Ein Bautechnikgeschichtliches Denkmal (Zimdars D and Wölbert O (eds)). Konrad Theiss Verlag, Darmstadt, Arbeitsheft 27 der Landesdenkmalpflege Baden-Württemberg, Esslingen, Germany, pp. 63-74 (in German).

Gerhardt HJ, Boller U and Kuhlmann W (2013) Windlastannahmen für Kirchturmhelme. Bauingenieur Fachteil Windtechnologie 88(9): 2-5 (in German).

Kayser C (2014) Die Baukonstruktion des Turmhelms des Freiburger Münsters - Bestand und Kontext. In Der Turmhelm des Münsters Unserer Lieben Frau in Freiburg - Ein Bautechnikgeschichtliches Denkmal (Zimdars D and Wölbert O (eds)). Konrad Theiss Verlag, Darmstadt, Arbeitsheft 27 der Landesdenkmalpflege Baden-Württemberg, Esslingen, Germany, pp. 75-122 (in German).

Szalay Z (1983) Wind loads on ancient church spire. Journal of Wind Engineering and Industrial Aerodynamics 11(1-3): 187-199, http://dx.doi.org/10.1016/0167-6105(83)90099-5.

\section{WHAT DO YOU THINK?}

To discuss this paper, please submit up to 500 words to the editor at journals@ice.org.uk. Your contribution will be forwarded to the author(s) for a reply and, if considered appropriate by the editorial panel, will be published as a discussion in a future issue of the journal.

Proceedings journals rely entirely on contributions sent in by civil engineering professionals, academics and students. Papers should be 2000-5000 words long (briefing papers should be 1000-2000 words long), with adequate illustrations and references. You can submit your paper online via www.icevirtuallibrary.com/content/journals, where you will also find detailed author guidelines. 